\title{
Study on Key Technologies of Shipbuilding Virtual Enterprise Information Integration Oriented Agile Manufacturing
}

\author{
Zhiying Wang and Shilun Ge \\ Economy and Management School, Jiangsu University of Science and Technology, \\ Zhenjiang 212003, Jiangsu, P.R.China wangzy_20066@163.com jzgsl@jzerp.com
}

\begin{abstract}
The paper takes the shipbuilding enterprise as the subject of study, analyzes the market pattern of world shipbuilding enterprise, presents shipbuilding virtual enterprise based on agile manufacturing according to the present situation and development trend of our shipbuilding enterprise, and describes the solution scheme of shipbuilding virtual enterprise information integration platform. The platform is open, loose coupling and dynamic oriented agile manufacturing, based on XML technology, workflow technology and web service technology. The platform supports the cross platform operation and isomeric configuration data exchange, and has the standard foreign connection and integrates carry-over systems. Enterprise application integration among various shipbuilding enterprises can be realized automatically and agilely through this platform under the internet environment. Therefore, a certain reference value frame is provided for the further research and the practical application of the shipbuilding virtual enterprise.
\end{abstract}

Keywords: Enterprise information integration, Virtual enterprises, Web services, Work flow management, Enterprise modeling and integration

\section{INTRODUCTION}

Modern manufacturing system is developing in the direction of networking, digitization, the intelligentization, and virtualization. In the $21^{\text {st }}$ century that is characterized by information and knowledge, the markets change frequently, new technologies constantly emerge, competitors spread all over the world. The manufacturing industry is consequently required to adjust itself to this new environment. Under such circumstance, agile manufacturing has become the general tendency of manufacturing industry in the $21^{\text {st }}$ century, while an important means to realize agile manufacturing is virtual enterprise [1-3]. Virtual enterprise is the major organization form of enterprise in the $21^{\text {st }}$ century and important method to make the enterprise more competitive. Multi-level and all-around information frame can provide powerful support to the integration and implementation of virtual enterprise. Effective integration can not only promote the agility of virtual enterprise,

Please use the following format when citing this chapter:

Wang, Z., Ge, S., 2007, in IFIP International Federation for Information Processing, Volume 255, Research and Practical Issues of Enterprise Information Systems II Volume 2, eds. L. Xu, Tjoa A., Chaudhry S. (Boston: Springer), pp. 961-969 
maximizing the rational distribution of resources and the value of products, but also bring the virtual enterprise more market opportunities, making them more competitive. With the development of network technology, it is necessary to adopt a new technology to study the integration method and information frame of virtual enterprise on the basis of existing research achievements about virtual enterprise, so that an open, loosely coupled, dynamic information platform can be established, that a frame of reference value can be provided to the further study and practice of virtual enterprise.

\section{NECESSITY OF ESTABLISHING INFORMATION INTEGRATION FRAME OF SHIPBUILDING VIRTUAL ENTERPRISE}

In the manufacturing industry, the theory about virtual enterprise comes into being earlier. After the information and technology revolution [4], the virtual enterprise has been developing at a very fast speed. Because shipbuilding is a relatively special industry, the application of virtual enterprise is not as wide and obvious in this field as in other fields. In shipbuilding industry, virtual enterprise is mainly used in engineering construction, such as virtual construction, joint-producing pattern. As whole, the application and studies of virtual enterprise are focused on virtual construction. And these studies have laid a foundation for the further study of the application of virtual enterprise in shipbuilding industry. At present, the connotation of virtual enterprise is continuously being extended, but as far as its basic forms are concerned, there are two major types: the one is virtual enterprise having the loan of outside force. Damem shipbuilding enterprise in Netherlands is a typical example of this type. The other is virtual enterprise cooperating with each other, which is common in overseas shipbuilding industry. One typical example of this type is Euroyards in Europe. Virtual enterprise is a topic of general interest in present shipbuilding circles, and the research concerning it is in its beginning stages in each country.

China has been generally recognized in shipping circles and shipbuilding circles as a world shipbuilding base. Easterly transfer of shipbuilding center, coupled with the recovery of international ocean shipping and the growing demand for ships, provides Chinese shipbuilding industry a promising market and a profitable opportunity [5-6]. China now is formulating corresponding policies, promoting the enterprise' reorganization with the aim of improving shipbuilding industry's capability and structure, and cultivating large internationally competitive shipbuilding groups. In 2006, the number of ships made in China, the orders for new ships China takes, the orders for ships China holds respectively occupies $19 \%, 30 \%$ and $24 \%$ of the market shares [7]. China is taking a larger and larger proportion of world shipbuilding market. Now there is a tendency for world manufacturing industry to transfer, which offers a wonderful opportunity to Chinese enterprises.

Facing such fierce competition, only by taking advantage of information technology, combing advanced manufacturing technology and modern management mode, establishing integrated information system can shipbuilding enterprise become 
more competitive in a comprehensive way. Presently, the information system of domestic shipbuilding enterprise are mostly based on traditional kind of work in a factory specialization as a workshop of partition manufacturing, each system usually is an independent, isolated information island. The poorly designed and produced isomerous system cannot cooperate appropriately in management, nor can it achieve efficient data transfer and data interchange. It has become a trend for digital shipbuilding that to, with the help of overall digitization, overall modularizations, and network platform, achieve digital design, digital manufacturing, and digital management. According to the outline of the $11^{\text {th }}$ Five-year Plan, shipbuilding industry is a key industry that needs definite support. However, factors like lack of creativity, backward management, backward technology, are preventing China from becoming a great nation in the field of shipbuilding. In order to develop an enterprise structure in which shipbuilding enterprise of different scales occupy proper proportion respectively, develop harmoniously, China has to virtualize its shipbuilding industry by setting up shipbuilding virtual enterprise information integration platform, to promise the implementation of advanced shipbuilding technology, to promote the management level of its shipbuilding virtual enterprise, to present a new way of adjusting the structure of its shipbuilding industry. Virtual enterprises are based on professional division of labor. This division of labor benefits the formation of professional market pattern as well as the formation of new shipbuilding-structureadjusting strategy. It helps shipbuilding industry to establish external cooperating network, to take full advantage of external resources and centralize the limited resources on developing the core capability of enterprise. This thought for development is especially important for China's shipbuilding industry. It can realize a diversified economy, separate minor business from key business hence cultivating new core competitive power. It can also improve Chinese shipbuilding industry's competitive ability and sequentially reach a new height in shipbuilding industry.

\section{INFORMATION INTEGRATION MODEL OF SHIPBUILDING VIRTUAL ENTERPRISE}

\subsection{Goal of Information Integration of Shipbuilding Virtual Enterprise}

The component parts of shipbuilding virtual enterprise scattered all over the world and, they organize and manage independently. As a result, in order to optimize and keep function the dynamic enterprises union, the architecture of shipbuilding virtual enterprise is required to have good nature in dynamic reconstruction, integration and opening. The specific requirements are as follows: trans-platform running, supporting kinds of application-system data exchange, system integration, extensive modularization, high-quality reliability and security, extendable business frame, having standard external interface. 


\subsection{Overall Structure Concerning Information Integration Model of Shipbuilding Virtual Enterprise}

In the light of its goal analysis and the information source, shipbuilding virtual enterprise is equal to isomerous database environment, rather colossal and complicated. For the goal of sharing the information resources, the incompatibility between the information form and information structure should be worked out. And suitable technology must be applied to the process of data analysis, integration and disposal. Irrelevant to program language as well as the running platform, web service, a distributed technology of new generation, is capable of running through firewall [810]. Thus, with the solution project on the basis of web service, the integration of application system would be easily attained between shipbuilding enterprise, which is self-controlled, automatic and rarely manually interfered in the Internet environment. Apart from that, the project could facilitate the integration of service from shipbuilding member enterprises. The overall structure is illustrated as figure 1 .

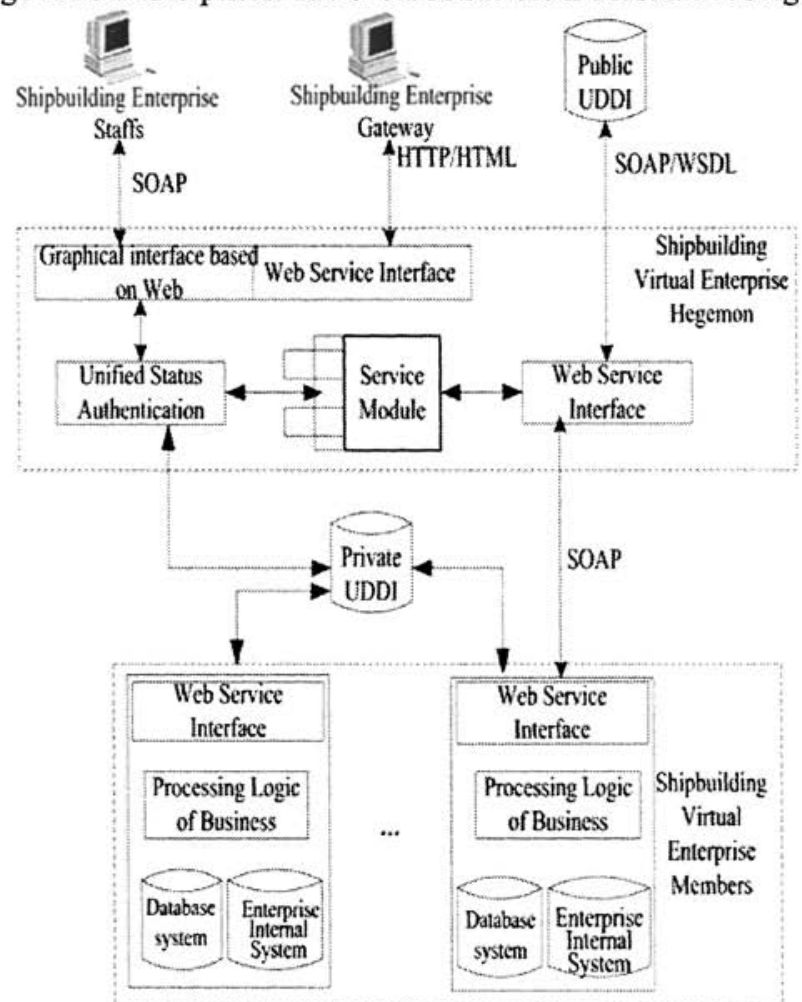

Figure 1. Overall Structure Concerning Information Integration Model

This information integration platform consists of the leader of shipbuilding virtual enterprise, member shipbuilding virtual enterprise, customer terminal. The leader of 
virtual shipbuilding enterprise is web service consumer, member shipbuilding virtual enterprise are web service provider, while the customer terminal is the terminal user of web service. Implementing the function of leader shipbuilding virtual enterprise is the key issue to the establishment of virtual enterprise information integration system.

\subsection{Workflow Architecture}

Information integration model of shipbuilding virtual enterprise combines web service with workflow technology [11] of virtual enterprise. The core of this model is that the shipbuilding enterprise publishes the shared business process as web service, so that other shipbuilding enterprise can use it. With web service, leader shipbuilding enterprise and member shipbuilding enterprise can access information in different platforms and systems at real time. As a result, the shipbuilding virtual enterprise' information integration requirements in the dynamic, loosely coupled environment are satisfied. The workflow system structure of the shipbuilding virtual enterprise is illustrated as figure 2 .

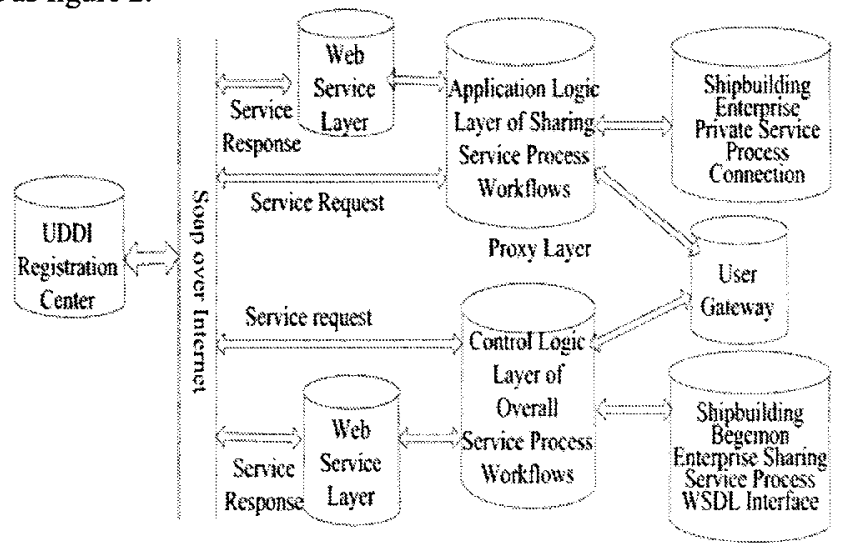

Figure 2. Workflow System Structure of the Shipbuilding Virtual Enterprise

\subsection{Enterprise's Internal Information Integration Architecture}

Different shipbuilding enterprise' internal carry-over systems may be built on different distributed platforms. If one wants to use web service technology to make integration, one only needs to encapsulate the distributed object as web service, then publish it. In this way, the carry-over systems are smoothly transferred from internal distributed platform to trans-enterprise distributed platform without changing its frame and logic. The internal information integration architecture of shipbuilding enterprise is illustrated as figure 3 . 


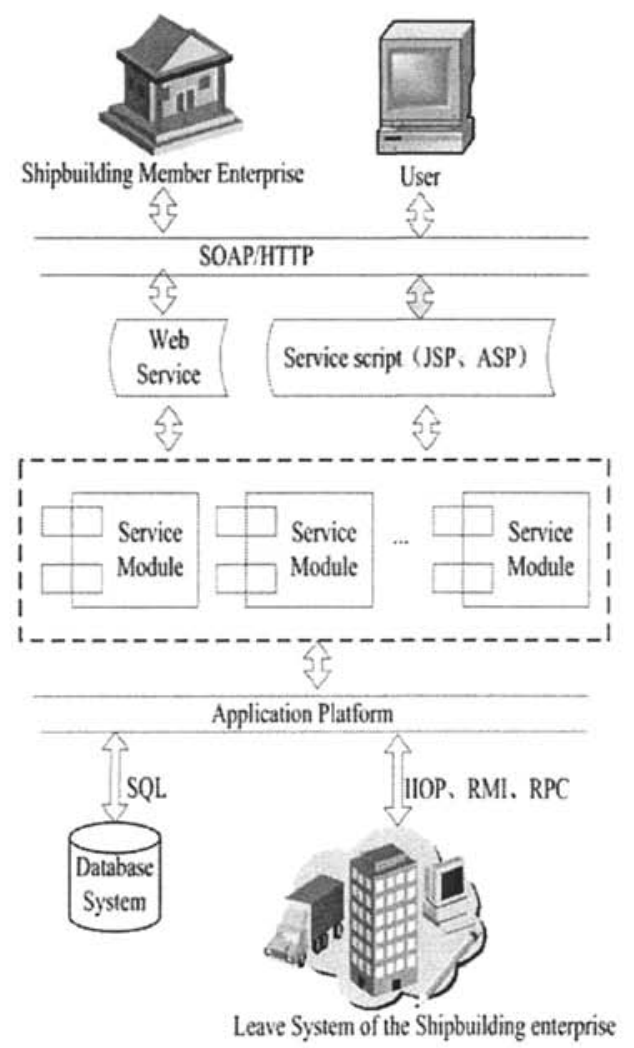

Figure 3. Internal Information Integration Construction of the Shipbuilding Enterprise

\section{PLAN FOR REALIZING INFORMATION INTEGRATION MODEL OF SHIPBUILDING VIRTUAL ENTERPRISE}

The plan for carrying out information integration frame of shipbuilding virtual enterprise is as follows: on the basis of XML(eXtensible Markup Language) technology[12], to make it come true that servers and users transfer message and data stream; to equally and conveniently interchange data in the form of objects between application programs according to SOAP(Simple Object Access Protocol) agreement; to use WSDL(Web Service Description Language) to define a standard representation mechanism of components based on XML; to describe necessary details with WSDL for the purpose that service consumer is able to use specific service; by UDDI(Universal Description, Discovery, and Integration) general description, discovery and integration agreement, to provide a web-based distributed standard mechanism of registering, publishing and web service finding; to combine web service with virtual enterprise workflow technology; member shipbuilding enterprise 
provide other shipbuilding enterprise with shared business process as web service, so that the information integration of shipbuilding virtual enterprise would be dynamic and loosely coupled.

The technology line based on web service to realize shipbuilding virtual enterprise's information integration platform is illustrated as figure 4.

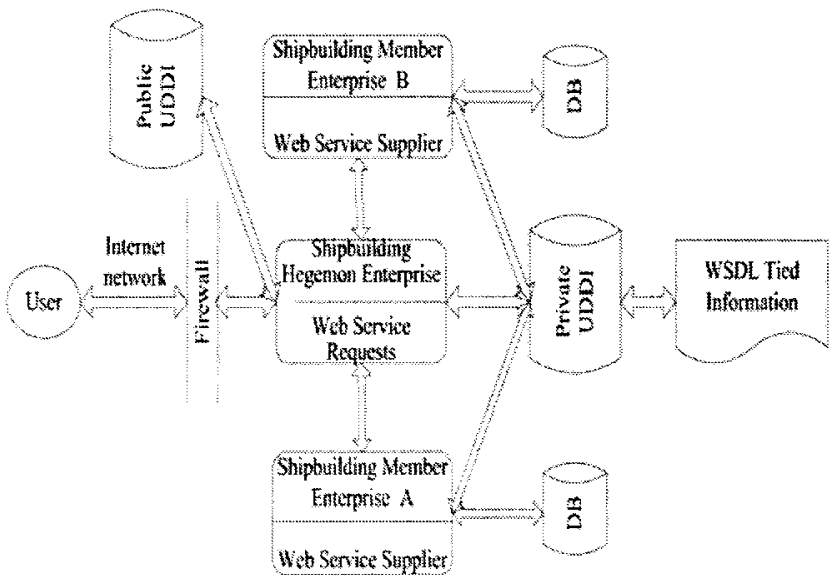

Figure 4. Technical Route of Integration Information Model

When deciding to set up shipbuilding virtual enterprise, leader shipbuilding enterprise inquires about the entity information of registered enterprise that register at the public UDDI register center and the information provided by these registered enterprise. It exchanges the information with service provider via SOAP/WSDL communication standard. After that it finally assesses and selecgs the enterprise.

By searching private UDDI register center, net-platform-based leader shipbuilding enterprise obtains related web service technology information that are provided by member enterprise' J2EE(JAVA 2 Platform Enterprise Edition) application server. WSDL binding information that is in accordance with designated web service is transferred to leader shipbuilding enterprise as SOAP-based information.

The whole frame is built on the basis of XML technology, while information is transferred by SOAP.

The safety of running is a key issue to virtual enterprise. This implementation plan is based on SOAP information monitoring. It combines federated identification with contract management, adopts asymmetric cryptographic algorithm, employs certificate management and digital signature to identify users.

\section{CONCLUSIONS}

This information integration model is based on the current situation of the shipbuilding industry in the world as well as the potential demand of shipbuilding industry. In the light of demand for informatization of manufacturing industry and the 
trend of development of advanced manufacturing technology, on the basis of existing research achievements, it conducts in-depth research on integration method and information frame. It also provides a valuable frame for the further research and practical application in China's shipbuilding industry by creating an open, dynamic, loosely-coupled platform. By constructing virtual enterprise oriented agile manufacturing, it virtualizes Chinese shipbuilding industry, provides a steady support for implementing advanced technology in shipbuilding industry. In addition, it improves the management level of China's shipbuilding industry, presents a new way of thinking for its structure adjustment. Most importantly, it enables China to take full advantage of external resources by constructing an external network and concentrate limited resources on developing the core capability of enterprise, which would be of more significance to our shipbuilding industry.

\section{ACKNOWLEDGEMENTS}

This research was supported by Shipping Advanced Design and Manufacture Technique Emphasis Laboratory of Jiangsu Province of China (CJ0605), supported by Colleges and Universities Natural Science of Jiangsu Province of China (06KJD120062) and supported by Research Institute of Humanities and Social Sciences of Jiangsu University of Science and Technology, China (2006JG005J).

\section{REFERENCES}

1. B.Q. Huang, The Theory and Technology of Virtual Enterprise System (Machinery Industry Press: Beijing, PK, 2004).

2. J. Chen and W.D. Feng, The Construction and Management of Virtual Enterprise (Tsinghua University Press: Beijing, PK, 2002).

3. H. Tian and Y.Q. Liu, The application prospect of the virtual enterprise in Chinese, Technoeconomics \& Management Research. Number 1, pp.66-67, (2000).

4. R.X. Wang, The Introductory of Advanced Mamufacturing Technique (Science Press: Beijing, PK, 2004).

5. J.Y. Wu, Several discussions on developmental strategy choice about our country shipbuilding technique, Technology and Economy Information of Shipbuilding Industry. Number 4, pp.12-17, (2001).

6. Y.G. Zhang, L.J. Dong, and C.P. Li, Development and prospect of the shipbuilding industry along the coast of China, Areal Research and Development. Volume 22, Number 2, pp.16-20, (2003).

7. Anonymous, E-Markets: The National Shipbuilding Industry Economy Movement Report of 2006, Management Office of Shipbuilding Industry (2007). http://www.costind.gov.cn/n435777/n569696/n569705/n569714/93363.html (Accessed March 27, 2007).

8. S.L. Yang, Y. Liu and X.J. Ma, Virtual enterprise solution based on web services and service-oriented architecture, Application Research of Computers. Volume 22, Number 10, pp.36-38, (2005).

9. A.Y. Li, The Technique and Realization of Web Services (National Defence Industry Press: Beijing, PK, 2003). 
Study on Key Technologies of Shipbuilding Virtual Enterprise Information Integration Oriented Agile Manufacturing 969

10. B.S. Amaud and R.B.O. Cherkaouj, Web service architecture for user control and management of optical internet networks, in Proc. of the IEEE. Volume 92, Number 9 , pp.1490-1500, (2004).

11. C.G. Huang, A.J. Trappey, and Y.H. Yao, Developing an agent-based workflow management system for collaborative product design, Industrial Management \&Data Systems. Volume 106, Number 5, pp.680-699, (2006).

12. Z.G. Xiong, X.M. Zhang, and J.X. Chen, The integration research of information system based on XML, Journal of Information. Volume 24, Number 6, pp.25-27, (2005). 